\title{
Drifter observations in the summer time Bay of Biscay slope current
}

M. Porter ${ }^{a}$ M. E. Inall ${ }^{a}$ J. A. M. Green ${ }^{b}$ J. H. Simpson ${ }^{b}$ A. C. Dale ${ }^{a}$ P. I. Miller ${ }^{c}$

${ }^{a}$ SAMS, Scotland.

${ }^{\mathrm{b}}$ School of Ocean Sciences, Bangor University, Wales.

${ }^{\mathrm{c}}$ Plymouth Marine Laboratory, England,

Corresponding author:

Marie Porter, SAMS, Scottish Marine Institute, Oban, Argyll, PA37 1QA, Scotland.

Email: mapo@sams.ac.uk

Phone: +44 (0)1631 559269

\section{Abstract}

During the summer of 2012, 20 surface drifters drogued at $50 \mathrm{~m}$ depth were deployed on the continental slope to the north of the Bay of Biscay. Initially after release the drifters all crossed the slope, with 14 continuing equatorward, parallel to the slope following an absolute dynamic topography feature and 6 returning to the slope, in an eddy, visible in chlorophyll-a maps. Lagrangian statistics show an anisotropic flow field that becomes less tied to the absolute dynamic topography and increasingly dominated by diffusion and eddy processes. A weaker tie to the absolute dynamic topography allowed for total of 8 of the drifters crossed from the deep water onto the shelf, showing pathways for flow across the slope. A combination of drifter trajectories, absolute dynamic topography and chlorophyll-a concentration maps have been used to show that small anticyclonic eddies, tied to the complex slope topography provide a mechanism for on shelf transport. During the summer, the presence of these eddies can be seen in surface chlorophyll-a maps.

\section{Key Words}

Drifters

Bay of Biscay

lagrangian statistics

Cross-slope exchange

\section{Highlights}

- A summer release of $\mathbf{2 0}$ drifters on the Bay of Biscay slope

- Lagrangian statistics for the Bay of Biscay reveal diffusive system

- On-shelf flow through genesis of small, anticyclonic eddies over complex topography 


\section{Introduction}

The Bay of Biscay, in the North East Atlantic, has a deep $(4000 \mathrm{~m}+)$ abyssal plain that is separated from the continental shelf by a steep and irregular shelf break (Figure 1). The shelf break is oriented north-west to south-east and bounds the narrow $(\sim 60 \mathrm{~km})$ Aquitaine Shelf in the south-east, which widens (to $\sim 170 \mathrm{~km}$ ) further north becoming the Armorican Shelf.

Charria et al. (2013) described three independent flow regimes in the Bay of Biscay: over the abyss, at the shelf break, and on the continental shelf (Figure 1). Over the Bay of Biscay abyssal basin, the mean circulation tends to be cyclonic in the winter (Pingree, 1993), with anticyclonic flow seen in the south-west corner during summer (Pingree and Le Cann, 1990; Charria et al., 2013). Transport across the slope is primarily through eddy shedding along the slope, both onto and off the shelf (Pingree and Le Cann, 1992b; Pingree and Le Cann, 1992a; van Aken, 2002) and mass flux within non-linear internal tides. Significantly, long-lived anticyclonic Slope Water Oceanic eDDIES (SWODDIES) (Pingree and Le Cann, 1992a) are known to advect slope water westwards into deeper water, after being shed from the southern slope during winter, and have been observed to remain established above the abyss for periods of the order of one year (Pingree and Le Cann, 1992a).

On the Armorican and Aquataine continental shelf, the currents are dominated by wind, tides and freshwater input from rivers (Pingree and Le Cann, 1989; Koutsikopoulos and Le Cann, 1996; Batifoulier et al., 2012), leading to significant variability in current patterns. However, a seasonally reversing mean flow is apparent which tends to be poleward in winter months and equatorward in summer (See Figure 1 and Pingree and Le Cann, 1989; Pingree and Le Cann, 1992b; Pingree, 1993; van Aken, 2002; Charria et al., 2013).

A seasonally varying current has also been identified over the slope (Pingree and Le Cann, 1990; Pingree, 1993; van Aken, 2002; Huthnance et al., 2009; Charria et al., 2013). The poleward manifestation of this current, which is observed throughout the winter months, peaks in speed in 
December with typical velocities at that time of $5 \mathrm{~cm} \mathrm{~s}^{-1}$ (Pingree and Le Cann, 1989), and forms part of the density driven European Shelf break Current (Huthnance et al., 2009; Xu et al., 2014). During the summer the mean flow is weaker and reversed, peaking at only $1.5 \mathrm{~cm} \mathrm{~s}^{-1}$ in June in an equatorward direction along the shelf break (Pingree and Le Cann, 1990; Huthnance et al., 2001; Charria et al., 2013). This reversal is thought to be driven by summer northerly winds (Pingree and Le Cann, 1989; van Aken, 2002). The seasonal reversal of the slope current in the region is collectively known as the SOMA (September/October - March/April) effect (Pingree, 1994), and has been verified by a number of drifter (Charria et al., 2013) and current meter (Pingree, 1994; Pingree et al., 1999) studies.

While the abyss, slope and shelf are all dynamically and hydrographically distinct regions, they are inevitably linked through the exchange of water across the slope. The transport of water across the shelf break is a crucial pathway for nutrients, such as nitrogen and phosphate, from the deep ocean onto the continental shelf (Liu et al., 2010). This import of nutrients from adjacent ocean basins makes shelf seas highly productive, providing around $90 \%$ of the world's commercial fish catches (Pauly et al., 2002). While covering only $7.6 \%$ of the ocean floor (Sverdrup et al., 1942) the productivity of the shelves give them a disproportionally high impact on the global carbon cycle. The

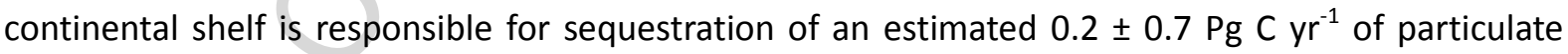
organic carbon, with the European shelf thought to be a carbon sink (Laruelle et al., 2014; Gruber, 2015). Consequently there is a wider need to fully understand this economically and climatologically sensitive region; improving our knowledge of the fluxes and exchange across the slope between ocean and shelf is an important part of this.

The complicated topography of the region and the strong poleward current seen during winter results in the shelf break being an eddy genesis region (Pingree, 1979; Dickson and Hughes, 1981; Pingree and Le Cann, 1992b; Garcia-Soto et al., 2002). This, combined with strong internal tides, persistent fronts and changeable winds mean that this is a highly variable and dynamic region. The 
present study was motivated by a desire to gain a detailed understanding of local intra-seasonal cross-slope exchange. We present analysis of new data that focuses on the slope region, comprising drift patterns of 20 drifters, all drogued at $50 \mathrm{~m}$ depth.

Although previous studies (Pingree and Le Cann, 1990; Pingree, 1993; Pingree et al., 1999; Charria et al., 2013) have identified the seasonal variability of the circulation of the Bay of Biscay, our knowledge of the variability of exchange (and therefore of all dissolved constituents) across the slope is limited. In order to investigate the intra-seasonal time scale, the drifters used in this study were deployed in June 2012 and were active through to January 2013, documenting the circulation of the Bay of Biscay during the transition from summer to autumn. This study highlights the processes behind cross-slope exchange and is complementary to previous descriptions of the circulation of the region. The paper has two notable outcomes: 1) it provides a Lagrangian statistical analysis of dispersion and diffusivity in the region, and 2) it provides a drifter based dataset which highlights the processes allowing on shelf flow along the Bay of Biscay slope. This drifter study adds to overall understanding of exchange processes across the European shelf break, as well as suggesting locations and mechanisms for persistent cross-slope flow.

The paper is structured as follows: in Section 2 the observations and the data organisation are presented. The mean flow of the drifters is described in Section 3. Lagrangian statistics are discussed in Section 4. Section 5 discusses kinetic energy and notable features of this study, and finally the conclusions are presented in Section 6.

\section{Instrumentation and methods}

On $14^{\text {th }}$ June 2012, 20 drifters were deployed in the northern Bay of Biscay as part of the FASTNEt project (Fluxes Across Sloping Topography in the North East Atlantic; See Figure 1 for the locations). The drifters were released between the $200 \mathrm{~m}$ isobath (approximately $07^{\circ} 18 \mathrm{~W}, 47^{\circ} 36$ ) and the 1000 $\mathrm{m}$ isobath (approximately $07^{\circ} 23 \mathrm{~W}, 47^{\circ} 32 \mathrm{~N}$ ), selected to reflect the positions of historical current 
meter data. Pingree and Le Cann (1989) collated current meter data collected between 1969 and 1988 and used these data to estimate an along-slope transport at $47^{\circ} 30 \mathrm{~N}$, quoting a figure of around 0.6 Sv. In addition to this, Pingree and Le Cann (1990) found flow speeds of between 5-10 $\mathrm{cms}^{-1}$ at depths of 3-500 $\mathrm{m}$ at approximately $47^{\circ} 30 \mathrm{~N}$, above the $500 \mathrm{~m}$ isobath. By selecting this as our deployment location our aim was to seed the core of the slope current with drifters at a location where seasonal reversal was anticipated to occur.

The drifters used in this study were MetOcean SVP (Surface Velocity Program) drifting buoys, with a holey-sock drogue (Sybrandy et al., 2009). While the use of a holey-sock drogue allows for subsurface water at drogue depth to be tracked it should be noted that, in high sea states, the drogue and tether are susceptible to breakages and loss. In addition, and even without drogue loss or damage, high wind states increase vertical shear in horizontal velocity from Stokes and Ekman dynamics which increases the influence of surface processes on the whole drifter package.

The drogues were centred at $50 \mathrm{~m}$ in order to be positioned below the predicted depth of the summer pycnocline and thus limit the effects of the wind on the drifter trajectories. This depth has been predicted using the NEMO $12^{\text {th }}$ degree model and indicates that the drogues were below the pycnocline until November, where they became part of the surface flow. The combined effects of background shear, wind and waves on the behaviour and water-following capabilities of the drifters can be represented by a so-called drag ratio. The drag ratio, in this case $40: 1$, is defined as the ratio between the drag area of the drogue and the combined drag area of the tether and the float (Sybrandy et al., 2009).

The excess downwind movement (termed the "wind slip") of SVP drifters is $\sim 0.1 \%$ of the wind speed for wind speeds up to $10 \mathrm{~m} \mathrm{~s}^{-1}$ (estimated using directional current meters attached to drifters (Niiler et al., 1995)). Above this wind speed, the wind slip is unknown.

Within this experiment the primary reason for drifter failure was loss of the drogue. Prior to 2002, 
SVP drifters consisted of a large surface buoy and a smaller subsurface one (Grodsky et al., 2011). This two-buoy system allowed for decoupling between the drogue and the surface motion, reducing the stresses and strains on the tether and the likelihood of drogue loss. Since 2002, with the development of the SVP mini drifter, the subsurface float is no longer part of the design. Decoupling between buoy and drogue is now reliant on lower tension in the tether (GDP, 2010) through buoy and drogue design. Despite these developments, strains on the tethers can produce high tension at which snapping occurs (Grodsky et al., 2011). In order for the results of this study to remain valid (i.e. tracking of water at drogue depth) it was imperative that drifter trajectories were excluded from the analysis from the point at which their tether broke. Drogue loss detection was achieved through the use of a strain gauge on the coupling between the drifter and tether, which records a large drop in tension if the drogue is lost or a large increase in tension if the drogue becomes snagged. Only those drifters with drogues still attached have been used in this analysis. The number of days for which each drifter was active (i.e. still with drogue attached and valid for analysis in this study) is given in Table 1.

Throughout the experiment the drifters reported their GPS-derived location and the sea surface temperature every 3 hours through Iridium satellites, with a spatial accuracy of $\sim 10 \mathrm{~m}$. Due to occasional float submergence in high seas, the transmissions did not always succeed and thus it was necessary to interpolate the data onto a regular 3-hour grid using a linear interpolation. The longest data gap that was interpolated in this manner was 12 hours.

In the shelf sea environment a wide spectrum of flows can influence drifter trajectories. On the Armorican Shelf this spectrum ranges from tides, particularly the M2, S2 and N2 constituents (Pérenne and Pichon, 1999), and inertial oscillations, with a period of approximately 16.6 hours at this latitude, to eddies and the mean circulation. In order to isolate the behaviour of the mean (subtidal and sub-inertial) cross-slope flow higher frequency motions were excluded. To remove dominant tidal and inertial signals, drifter positions were filtered, following the method of Burrows 
and Thorpe (1999), using a $10^{\text {th }}$-order, zero-phase, low pass Butterworth filter with a cut off at 1 cycle per day.

In order to allow for simple descriptions of along- and across-slope flows, a new co-ordinate system is introduced for this analysis, with the $x$-axis perpendicular to the $500 \mathrm{~m}$ isobath and the $y$-axis parallel to it. On-shelf and poleward flows are taken as positive in the new coordinate system. The orientation of the slope has been assumed to have a constant value of $50^{\circ}$ anticlockwise from north between the latitudes of $45^{\circ} \mathrm{N}$ and $48^{\circ} \mathrm{N}$, which is a good approximation to reality (Figure 1 ).

The $50 \mathrm{~m}$ tether was used to centre the drifters beneath the seasonal pycnocline. Although due to shear through the water column it is difficult to quantify the exact depth at which the water was tracked, and so the drifters should be seen as being largely representative of upper conditions.

Throughout the first months of the experiment (June, July and the first 2 weeks of August) average winds over the Bay of Biscay (between $44^{\circ} \mathrm{N}-48^{\circ} \mathrm{N}, 3^{\circ} \mathrm{W}-8^{\circ} \mathrm{W}$ ) from the NCEP/NCAR reanalysis product (NCEP/NCAR, 2014) were north-westerlies becoming south-westerlies, of the order of $5 \mathrm{~ms}^{-1}$. After August the wind direction became more variable, but maintaining a north-westerly mean, with higher speeds (Figure 2). The weaker winds between June and August are expected to allow a generally equatorward flow in the Bay of Biscay (Pingree and Le Cann, 1989).

\section{The mean flow}

After their release on the $14^{\text {th }}$ of June, above the continental slope the drifters spread from the slope, towards the deep water (Figure 3). They continued in this direction for approximately 1 week, after which they began to turn to flow equator-ward, in the along-slope direction. This equatorward flow bifurcated with 6 drifters returning to the slope, while the remainder continued to the southeast. Of those that were advected onto the slope none subsequently returned to deep water, but instead crossed onto the shelf.

The initial cross-slope flow halted once away from the slope region, in conjunction with the presence 
of a high absolute dynamic topography (ADT) feature (Figure 4 (a)) driving an equatorward current of approximately $15 \mathrm{cms}^{-1}$ (Figure 3). The equatorward flow largely followed the edge of the ADT anomaly to $45^{\circ} \mathrm{N}$, maintaining this speed throughout. At $45^{\circ} \mathrm{N}$ the drifters move briefly off-shore before starting to turn to the east, throughout this part of the experiment the drifters began to disperse, and largely to slow down, with speeds of 5-10 $\mathrm{cms}^{-1}$ (Figure 3). Here, the flow once more followed the ADT contours, albeit with a weaker relationship. The weaker relationship and low ADT gradient appears to allow for increased dispersion (Figure 4(b)).

Once separated the drifters continued along independent paths with many moving toward the slope region (Figure 4(c)), where the current speeds remained similar at 5-10 $\mathrm{cms}^{-1}$ (Figure 3), other than anomalous drifters, which exceeded $20 \mathrm{cms}^{-1}$ (Figure 3). Of the drifters that passed into the slope region 5 crossed onto the shelf, where they ultimately turned poleward within a winter coastal current.

It is clear within this description and Figure $4(\mathrm{a}-\mathrm{c})$ that the mean flow at $50 \mathrm{~m}$ depth, across this region, during the summer time is dominated by ADT gradients. However, conspicuously 6 drifters did not follow the pathway described, but quickly returned to the slope, in a current of over $20 \mathrm{cms}^{-1}$, (Figure 3) as the rest of the drifters started to flow equatorward. This does not seem to be linked to the ADT highlighting the importance of other processes. This cross-slope, on-shelf flow identified by these drifters will be further investigated in section 5 of this study.

Statistical analysis of the filtered and transformed, active (as previously defined) drifter trajectories is now introduced to describe the spatial and temporal evolution of the drifter array.

\section{Lagrangian displacement statistics}

Here we use pairwise relative dispersion to look at background turbulence and diffusivity of the flow field. Relative dispersion, derived from the separation of drifter pairs increases the degrees of freedom beyond the number drifters and allows for the characterisation of turbulent flows. In a 
turbulent flow, where separation distances are large relative to the typical length scale of energy containing eddies, dispersion will be high, while at smaller separation distances (relative to eddy size) dispersion will be lower (Lumpkin and Elipot, 2010). As the separation distance increases, the scale of features which dominate the calculated dispersion values also increases.

The relative dispersion $\left(D_{r x}^{2}\right)$ is defined as:

$D_{r x}^{2}=\overline{\left(s_{r x}-s_{r 0}\right)^{2}}$

where $s_{r x}$ is the separation distance between two drifters and $s_{r 0}$ is the initial separation of the same two drifters, both in the across-shelf $(x)$ direction and the overbar represents the mean over all drifter pairs. The rate of change of the dispersion gives the diffusivity $\left(K_{x}\right)$, defined (Batchelor, 1952) as

$K_{x}=\frac{1}{2} \frac{d}{d t} D_{r x}^{2}$

similar quantities $D_{r y}{ }^{2}$ and $K_{y}$ are defined in the $y$ direction.

Dispersion and diffusivity have been calculated for the first 60 days of the experiment (Figure 4 and Figure 5), during which time the drogues were below (deeper than) the mixed layer and were advected along the Armorican and Aquitaine slope and adjacent basin (Figure 3), not yet under the influence of the bathymetric "corner" near to the Cape Ferret Canyon (Figure 1). A total of 13 drifters remained active throughout this 60 day period (Table 1). The relative statistics have been calculated using the full set of 91 drifter pairs (selected from the 13 active drifters) whose initial separation distances were $\leq 5 \mathrm{~km}$. The use of $5 \mathrm{~km}$ as the pair selection criterion gave a large number of pairs while retaining similarity of the regime at the point of release.

\subsection{Along-slope dispersion and diffusivity}

In the along-slope direction, the initial 13 days after release followed a $t^{2}$ curve with a $R^{2}$ of 0.95 $(p<0.01)$, showing almost no dispersion over the first 6 days, with a rapid increase over the following 
7 days (Figure 5). This represents the time during which the drifters crossed out of the slope region and began to turn to flow equatorward.

After day 13 the dispersion of the drifters in the along-slope direction slowed and the drifter pairs began to converge, as they left the fast equatorward current and began to follow independent paths. From approximately day 30 until 50 , the drifters accelerated. Here the dispersion followed a $\mathrm{t}^{3}$ curve with a $R^{2}$ of $0.94(p<0.01)$, reflected in a marked increase in the diffusivity (Figure $\left.6(a)\right)$. Such $t^{3}$ behaviour suggests a fully turbulent flow, obeying Kolmogorov similarity theory (Okubo, 1971), in which the system is dominated by shear and turbulent eddies (Koszalka et al., 2009). This observation of $\mathrm{t}^{3}$ flow corresponds with the period during which the flow is no longer tied to the locally weakened ADT gradient.

\subsection{Across-slope dispersion and diffusivity}

The initial growth in the across-slope direction follows a $t^{2}$ curve $\left(R^{2}=0.96, p<0.01\right)$ over the first 10 days (Figure 5), as the drifters cross the slope. Once away from the slope region the across-slope flow tends to an approximately linear, t regime $\left(R^{2}=0.82, p<0.01\right)$. Within such a regime the drifters are separating at a constant rate (Figure 5 and Figure $6(\mathrm{~b})$ ), subject to Fickian diffusion in a cross-slope sense, again corresponding to the period during which the ADT flow of the water is not dominated by the ADT.

These dispersion statistics reveal an anisotropic environment, with dispersion scales of between $7 \times 10^{9}$ and $8 \times 10^{9} \mathrm{~m}^{2}$ over 60 days in both the along and across slope directions. In the along slope direction the relative dispersion was dominated by turbulence and shear, while in the across slope direction the separation of the drifters was driven mostly by diffusive processes.

Within the first 60 days of the release, which were the focus of this statistical study, only 3 crossed the slope. During this period the drifters spread across the bay, often towards the slope, however, these primarily remained above the abyssal plane. The remainder of this study will look at the 
locations at which the drifters left the abyssal plane to cross the slope, and the potential drivers of such flow.

\section{Cross-slope flow}

Of the 20 drifters in this study, a total of 8 crossed the shelf break (the $200 \mathrm{~m}$ isobath) between the $16^{\text {th }}$ of July and the $10^{\text {th }}$ of October and remained on the continental shelf thereafter, suggesting that not only does water cross onto the shelf region from the deep ocean, but that it stays there (Figure 3). The energy contained within this flow can highlight regions of cross-slope flow.

\subsection{Kinetic Energy}

Fluctuations of the current velocity superimposed on the mean flow can be quantified by the eddy kinetic energy, defined as:

$$
E K E=\frac{1}{2} \overline{\left(u^{\prime 2}+v^{\prime 2}\right)}
$$

with $u^{\prime}=u-\bar{u}$, where $u$ is the low pass filtered velocity component in the zonal direction (filtered as described in Section 2) with the overbar indicating the mean within the local $0.25^{\circ} \times 0.25^{\circ}$ spatial box (Richardson, 1983) and ( $v^{\prime}$ is defined accordingly). Following Morrow et al. (1994) such energy can be represented as the sum of the major and minor axis of the covariance matrix, allowing for further information on the isotropy of the flow. Mean kinetic energy (MKE), indicating the strength of the local current at a given location is defined as:

$$
M K E=\frac{1}{2} \overline{\left(u^{2}+v^{2}\right)}
$$

Both MKE and EKE were calculated from the release for 130 days, during which time the drogues of the drifters remained beneath the MLD and the average wind speeds, were around $3 \mathrm{~ms}^{-1}$ and had not begun to reflect higher speeds, typical of the winter environment.

A map of variance ellipses and MKE (Figure 7) shows the highest MKE values to be over 3 
independent parts of the slope region, concurrent with the areas of high EKE. The absence of a peak in MKE along the entirety of the slope indicates, as expected, the absence of a well-defined summer slope current.

The high EKE and MKE values appear to be associated with the regions of most irregular topography, suggesting a link between these topographical features and cross-slope exchange. Understanding the dynamics behind these localised features is important for our understanding of the biogeochemical and ecological systems of the region.

\subsection{Drivers of the cross-slope flow}

Through the conservation of potential vorticity the flow of water will follow contours of potential vorticity and as such will not cross bathymetric features in the absence of an external forcing mechanism. Here we will discuss potential drivers of such cross-slope flow in the Bay of Biscay.

Here we will use maps of chlorophyll-a and ADT, in addition to the drifters, to follow potential exchange features in the region. Throughout the summer when wind-forced surface mixing is low, surface chlorophyll-a concentration can be used to track the movement of surface water. Strictly, chlorophyll-a is not a conservative tracer however, during the summer, it tends to be in low concentrations over the abyss and higher concentrations over the shelf. The slope tends to act as a boundary between the two regimes, and it is often the location of chlorophyll-a blooms due to intense vertical mixing through the action of internal waves/tides (Pingree et al., 1986), giving rise to a spatial maximum in chlorophyll-a over the shelf break and slope region. Clearly chlorophyll-a is a surface tracer and so in the presence of summer stratification its movement will not simply be indicative of that at the depth of the drifter drogues. Nevertheless in combination with ADT maps, the movement of eddies can be observed by tracking anomalies in the chlorophyll-a satellite images (Chelton et al., 2011).

The chlorophyll-a maps used here (Figure 8) are 3-day median composites from the MODIS sensor on 
the Aqua satellite (NASA, 2014). These composites were selected in preference over the 30-day ones as they allow for the identification of mesoscale features that would be smoothed out in the longer term averages. In July 2012, shortly after the drifter release, the shelf break is largely visible as a band of high chlorophyll-a (Figure 8 (a)). After release the drifters follow an off-shelf extrusion of high chlorophyll-a water, in what appears to be a cyclonic eddy (Figure 9), from the shelf-break towards the abyssal plain. There the drifter cloud bifurcates with some drifters leaving this eddy to flow equatorward and the remainder moving around the (apparent) eddy back towards the slope region. This eddy appears to persist throughout July. However, by August, approximately day 50, all of the active drifters had left this region, either crossing the slope to the north or continuing to the south.

As the remainder of the drifters move towards the south they largely track ADT features, as discussed in Section 3. However the diffusive processes identified within the lagrangian statistics in Section 4 show the spread of the drifters in a cross-slope sense is beyond the influence of the ADT. Of the drifters that reach the slope a further 7 cross the slope, 6 in 2 regions near to the Cap Ferret Canyon (Figure 3) and 1 further south at the Sables d'Olonne Canyon (Figure 3). All 3 of these regions are areas of high EKE/MKE, consistent with the genesis of eddies in these topographically complex sections of slope.

Within the trajectories of the drifters that cross the slope, a number of small anticyclonic loops have been identified, while near to the shelf-break (Figure 10). Of these loops 3 full circles were completed, amongst a number of part ones. These apparent anticyclonic eddies have diameters of approximately $5-12 \mathrm{~km}$ and drifters take $3-5$ days to finish 1 rotation, giving an azimuthal velocity of $\sim 10 \mathrm{cms}^{-1}$. These short-lived eddies are comparable in both size and location to those identified by Serpette et al. (2006), which were noted in 1997 and 1998. The repeated observations of these features in 1997, 1998 and 2012, in isolated regions along the Armorican Slope shows that these are not one-off features, dependant on the conditions during the specific year. The northern-most of 
these eddies at $47.25^{\circ} \mathrm{N}, 6.3^{\circ} \mathrm{W}$ follows a low chlorophyll-a signal, that extends from the slope onto the shelf, indicating the transport of off-shelf water across the slope and onto the shelf.

In contrast the northern-most, the signals of these eddies are not immediately obvious in either the ADT or the chlorophyll-a images. However, shelf-wards of the eddy genesis regions there are low chlorophyll-a signals, indicating the presence of ocean/slope water on the shelf. These signals combined with the drifter trajectories show that water which crosses the slope can remain on the shelf, and does not necessarily immediately return to the abyssal region. Such chlorophyll-a signals may also be used to identify this process in subsequent years.

Only one of the slope crossing events occurred during the winter. Drifter 19 crossed the shelf-break 184 days after release, on the $15^{\text {th }}$ of December. During this time, the MLD had exceeded drogue depth and consequently the wind will have influenced its track. However, this drifter behaved similarly to those that crossed in the summer, with small, on-shelf propagating anticyclonic eddies identifiable within the trajectory. By December we would expect the winter slope current to be established and the region to therefore be subject to eddies that track from the shelf towards the abyss. As such it is particularly interesting to observe an on-shelf eddy at this time of year, although this is no longer identifiable within the chlorophyll-a images.

The similar size, location and speed of these eddies across multiple years and into the winter, indicates that they are not highly dependent on hydrographic conditions, but more likely on the topography. The eddy genesis regions are co-located with the most topographically complex sections of the slope. Changes in relative vorticity associated with canyons and promontories can disrupt the local flow, creating instabilities. The drifter trajectories presented within this study show that in the Bay of Biscay anticyclonic eddies in regions of complex slope topography provide a pathway for crossshelf flow.

Within this study 8 drifters crossed the slope in the Bay of Biscay. Satellite Chlorophyll-a 
concentration maps overlaid with the tracks of the drifters suggest that the drifters and likely the sub-pycnocline water, at drogue level, are able to cross the slope within short lived anticyclonic eddies. During the winter this process can no longer be observed in the satellite images, but the one drifter that crosses the slope in December show evidence of such eddies. On-shelf flow during these times seems to be closely tied to the slope bathymetry, where canyons and promontories can cause instabilities in the flow.

\section{Conclusion}

Twenty drifters were released as part of a study into cross-slope flow along the European Shelf Edge. Following the release of these SVP drifters drogued at $50 \mathrm{~m}$, on the Bay of Biscay slope in June 2012 they all quickly crossed into the abyssal basin and in general travelled equatorward from there along contours of $A D T$, in agreement with the SOMA effect. A total of 8 drifters crossed back from the abyssal basin onto the shelf, isolated. A combination of satellite images and drifter trajectories suggest that during the cross-slope flow is largely driven by small scale local eddy dynamics.

Lagrangian dispersion statistics have been calculated for the drifter trajectories over the first 60 days of the release, during which time the drifters tended to stay over the abyssal plain. These statistics describe a diffusive environment, where the flow in both the along- and across-slope directions is affected by turbulent eddies. EKE values, calculated on a grid, corroborate the statistical findings of an eddy rich environment over the slope.

Acknowledgements: This work was funded by the Natural Environmental Research Council through grants NE/I030224/1 (FASTNEt consortium) and NE/F014821/1 (Advanced Fellowship awarded to JAMG). The authors thank the efforts of Roger Scrivens at RS Aqua for help with purchasing the drifters. The authors also thank the expertise and commitment of the crew on Discovery cruise D376, and are grateful to the NERC Earth Observation Data Acquisition and Analysis Service (NEODAAS) for supplying data for this study. 


\section{References}

Batchelor, G. K. (1952). "Diffusion in a field of homogeneous turbulence." Mathematical Proceedings of the Cambridge Philosophical Society 48(02): 345-362.

Batifoulier, F., P. Lazure and P. Bonneton (2012). "Poleward coastal jets induced by westerlies in the Bay of Biscay." Journal of Geophysical Research: Oceans 117(C3): n/a-n/a.

Burrows, M. and S. A. Thorpe (1999). "Drifter observations of the Hebrides slope current and nearby circulation patterns." Annales Geophysicae 17(2): 280-302.

Charria, G., P. Lazure, B. Le Cann, A. Serpette, G. Reverdin, S. Louazel, F. Batifoulier, F. Dumas, A. Pichon and Y. Morel (2013). "Surface layer circulation derived from Lagrangian drifters in the Bay of Biscay." Journal of Marine Systems 109-110, Supplement(0): S60-S76.

Chelton, D. B., P. Gaube, M. G. Schlax, J. J. Early and R. M. Samelson (2011). "The influence of nonlinear mesoscale eddies on near-surface oceanic chlorophyll." Science 334(6054): 328-332.

Dickson, R. and D. Hughes (1981). "Satellite evidence of mesoscale eddy activity over the biscay abyssal-plain." Oceanologica Acta 4(1): 43-46.

Garcia-Soto, C., R. D. Pingree and L. Valdés (2002). "Navidad development in the southern Bay of Biscay: Climate change and swoddy structure from remote sensing and in situ measurements." Journal of Geophysical Research: Oceans 107(C8): 28-21-28-29.

GDP (2010). "www.aoml.noaa.gov/phod/dac/gdp_drifter.php."

Grodsky, S. A., R. Lumpkin and J. A. Carton (2011). "Spurious trends in global surface drifter currents." Geophysical Research Letters 38(10): L10606.

Gruber, N. (2015). "Ocean biogeochemistry: Carbon at the coastal interface." Nature 517(7533): 148149.

Huthnance, J. M., H. Coelho, C. R. Griffiths, P. J. Knight, A. P. Rees, B. Sinha, A. Vangriesheim, M. White and P. G. Chatwin (2001). "Physical structures, advection and mixing in the region of Goban spur." Deep Sea Research Part II: Topical Studies in Oceanography 48(14): 2979-3021.

Huthnance, J. M., J. T. Holt and S. L. Wakelin (2009). "Deep ocean exchange with west-European shelf seas." Ocean Science 5: 621-634.

IFREMER/LOS (2011). Mixed Layer Depth Climatology website (www.ifremer.fr/cerweb/deboyer/mld) (accessed [09/06/2015]). 
Koszalka, I., J. LaCasce and K. Orvik (2009). "Relative dispersion in the Nordic Seas." Journal of Marine Research 67(4): 411-433.

Koutsikopoulos, C. and B. Le Cann (1996). "Physical processes and hydrological structures related to the Bay of Biscay anchovy." Scientia Marina 60: 9-19.

Laruelle, G. G., R. Lauerwald, B. Pfeil and P. Regnier (2014). "Regionalized global budget of the CO2 exchange at the air-water interface in continental shelf seas." Global Biogeochemical Cycles 28(11): 2014 GB004832.

Liu, K.-K., L. Atkinson, R. A. Quiñoes and L. Talaue-McManus (2010). "Biogeochemistry of continental margins in a global context." Carbon and nutrient fluxes in continental margins: 3-24.

Lumpkin, R., S. A. Grodsky, L. Centurioni, M.-H. Rio, J. A. Carton and D. Lee (2013). "Removing Spurious Low-Frequency Variability in Drifter Velocities." Journal of Atmospheric and Oceanic Technology 30(2): 353-360.

Morrow, R., R. Coleman, J. Church and D. Chelton (1994). "Surface eddy momentum flux and velocity variances in the Southern Ocean from Geosat altimetry." Journal of Physical Oceanography 24(10): 2050-2071.

NASA (2014). "http://aqua.nasa.gov/about/instrument_modis.php." from http://aqua.nasa.gov/about/instrument_modis.php.

NCEP/NCAR (2014). "http://www.esrl.noaa.gov/psd/data/reanalysis/reanalysis.shtml."

Niiler, P. P., N. A. Maximenko and J. C. McWilliams (2003). "Dynamically balanced absolute sea level of the global ocean derived from near-surface velocity observations." Geophysical Research Letters 30(22): 2164.

Niiler, P. P., A. S. Sybrandy, K. Bi, P. M. Poulain and D. Bitterman (1995). "Measurements of the waterfollowing capability of holey-sock and TRISTAR drifters." Deep Sea Research Part I: Oceanographic Research Papers 42(11): 1951-1964.

Okubo, A. (1971). Oceanic diffusion diagrams. Deep sea research and oceanographic abstracts, Elsevier.

Pauly, D., V. Christensen, S. Guénette, T. J. Pitcher, U. R. Sumaila, C. J. Walters, R. Watson and D. Zeller (2002). "Towards sustainability in world fisheries." Nature 418(6898): 689-695.

Pérenne, N. and A. Pichon (1999). "Effect of barotropic tidal rectification on low-frequency circulation near the shelf break in the northern Bay of Biscay." Journal of Geophysical Research: 
Oceans 104(C6): 13489-13506.

Pingree, R. (1979). "Baroclinic eddies bordering the Celtic Sea in late summer." Journal of the Marine Biological Association of the United Kingdom 59(03): 689-703.

Pingree, R. (1994). "Winter warming in the southern Bay of Biscay and Lagrangian eddy kinematics from a deep-drogued Argos buoy." Journal of the Marine Biological Association of the United Kingdom 74(01): 107-128.

Pingree, R. and B. Le Cann (1990). "Structure, strength and seasonality of the slope currents in the Bay of Biscay region." Journal of the Marine Biological Association of the United Kingdom 70(04): 857-885.

Pingree, R. D. (1993). "Flow of surface waters to the west of the British Isles and in the Bay of Biscay." Deep Sea Research Part II: Topical Studies in Oceanography 40(1-2): 369-388.

Pingree, R. D. and B. Le Cann (1989). "Celtic and Armorican slope and shelf residual currents." Progress in Oceanography 23: 303-338.

Pingree, R. D. and B. Le Cann (1992a). "Anticyclonic eddy X91 in the southern Bay of Biscay, May 1991 to February 1992." Journal of Geophysical Research: Oceans 97(C9): 14353-14367.

Pingree, R. D. and B. Le Cann (1992b). "Three anticyclonic slope water oceanic eDDIES (SWODDIES) in the Southern Bay of Biscay in 1990." Deep Sea Research Part A. Oceanographic Research Papers 39(7-8): 1147-1175.

Pingree, R. D., G. T. Mardell and A. L. New (1986). "Propagation of internal tides from the upper slopes of the Bay of Biscay." Nature 321(6066): 154-158.

Pingree, R. D., B. Sinha and C. R. Griffiths (1999). "Seasonality of the European slope current (Goban Spur) and ocean margin exchange." Continental Shelf Research 19(7): 929-975.

Richardson, P. L. (1983). "Eddy kinetic energy in the North Atlantic from surface drifters." Journal of Geophysical Research: Oceans 88(C7): 4355-4367.

Serpette, A., B. L. Cann and F. Colas (2006). "Lagrangian circulation of the North Atlantic Central Water over the abyssal plain and continental slopes of the Bay of Biscay." Scientia Marina 70(S1): 2742.

Sverdrup, H. U., M. W. Johnson and R. H. Fleming (1942). the oceans their physics chemistry and general biology, Prentice-Hall Inc. 
Sybrandy, A., P. Niiler, C. Martin, W. Scuba, E. Charpentier and D. Meldrum (2009). "Global drifter programme barometer drifter design reference." DBCP Report 4.

van Aken, H. M. (2002). "Surface currents in the Bay of Biscay as observed with drifters between 1995 and 1999." Deep Sea Research Part I: Oceanographic Research Papers 49(6): 1071-1086.

Xu, W., P. I. Miller, G. D. Quartly and R. D. Pingree (2014). "Seasonality and interannual variability of the European Slope Current from 20 years of altimeter data with in situ measurement comparisons.

." Remote Sensing of Environment. 
Figure captions

Figure 1

The bathymetry of the Bay of Biscay, with some key features labelled. The release locations of the 20 SVP drifters are indicated by a black star at approximately $7.5^{\circ} \mathrm{W}, 47.5^{\circ} \mathrm{N}$. The bathymetric data are based on the GEBCO 1 min dataset (IOC et al., 2003). With the 4000, 3000, 2000, 1000, 500, 300 and $200 \mathrm{~m}$ contours shown. A Sketch of the main summer (April-September) flow pathways in the region is shown in red and the winter (October - March) pathways in blue (Charria et al., 2011).

Figure 2

The daily mean wind velocity at $10 \mathrm{~m}, \mathrm{x}$ is in the zonal direction and $\mathrm{y}$ the meridional. The values are calculated using the NCEP/NCAR reanalysis product, for the period of the drifter release. The red lines show the monthly means. The number of days since the drifter release are shown on the upper $x$-axis.

Figure 3

The filtered trajectories of the active drifters throughout this study. The trajectories are coloured by instantaneous speed of the filtered trajectories.

Figure 4

Absolute dynamic topography averaged for each month (June-August, a-c) with superimposed drifter trajectories for the same month.

Figure 5

(a) Dispersion time series for the filtered data during first 60 days following the drifter release. The coloured lines represent the different phases of Richardson's law pattern (Richardson, 1926) and a provided for reference purposes. Only drifter/pairs of drifters that remained fully active throughout the 60 days have been included here.

Figure 6

The along (a) and across (b) slope diffusivity for the dispersion curves shown in Figure 5.

Figure 7

Variance ellipses calculated from the drifter trajectories up until day 130. The sum of the major and minor axis is equal to the eddy kinetic energy. The coloured dots show the mean kinetic energy. Both of these are averaged over the $0.25^{\circ}$ boxes in which they are centred. The small circle in the lower right corner indicates $50 \mathrm{~cm}^{2} \mathrm{~s}^{-2}$.

Figure 8

Satellite Chlorophyll-a images from the MODIS sensor (NASA, 2014), with drifter tracks overlaid. The images are 3 day composites of the last two days of the previous month and the first one of the current (July-November a-e). The drifter tracks are those of the corresponding month, with the squares indicating the start point for each month and the diamonds the drifter locations at the time of the satellite image.

Figure 9

Zoomed in chlorophyll-a image for mid-July highlighting an intrusion of high concentration water 
from the shelf-break towards deeper water. This appears to show the presence a cyclonic eddy.

\section{Figure 10}

The track of one drifter, coloured by time, showing two small anticyclonic eddies over a region of complex slope topography. 


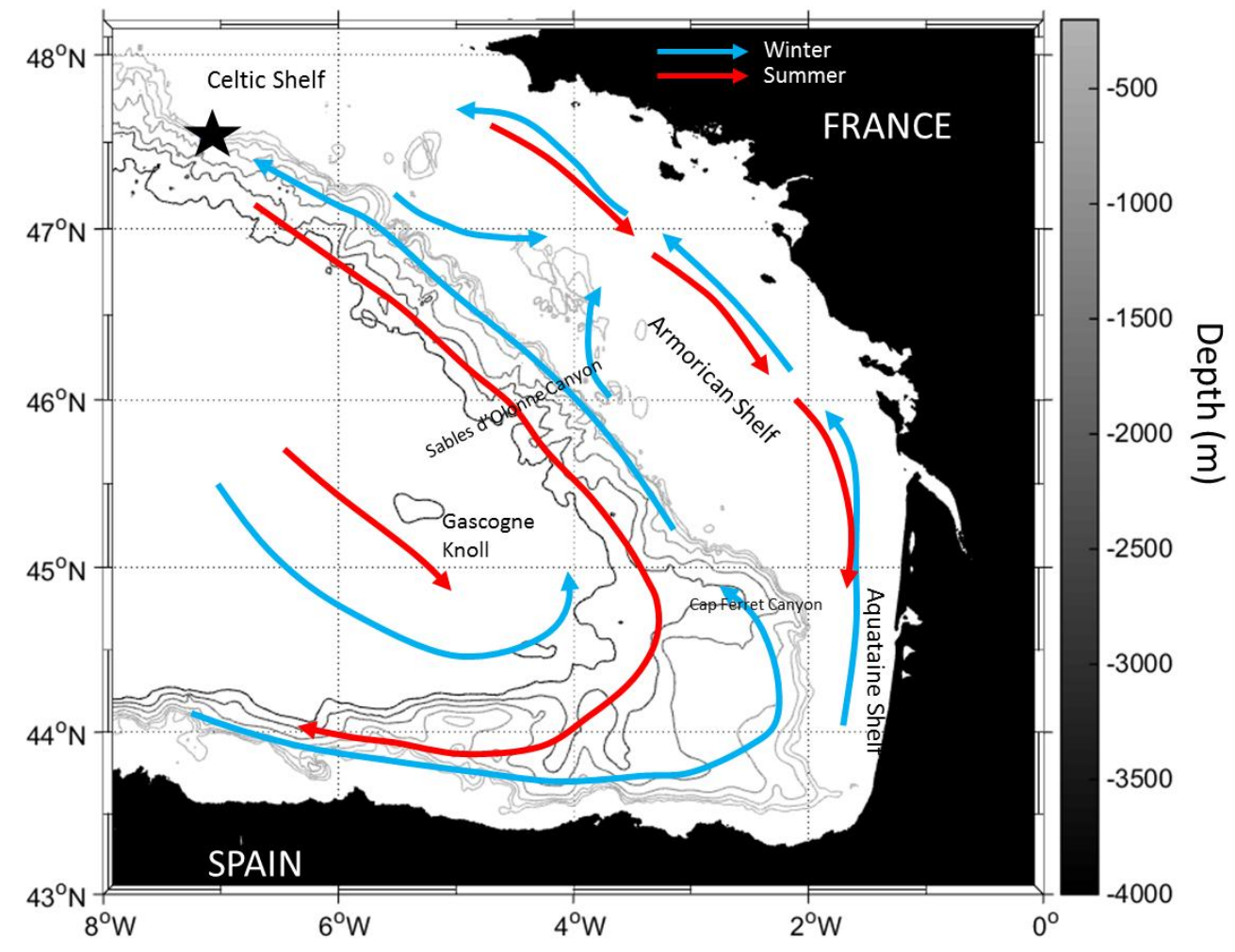

Figure 1 


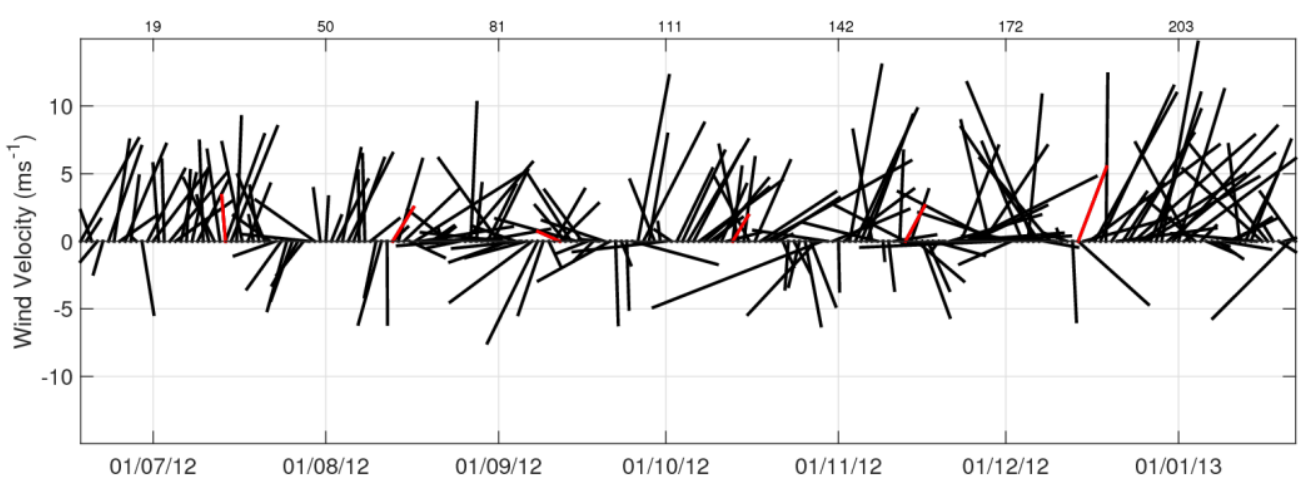

Figure 2 


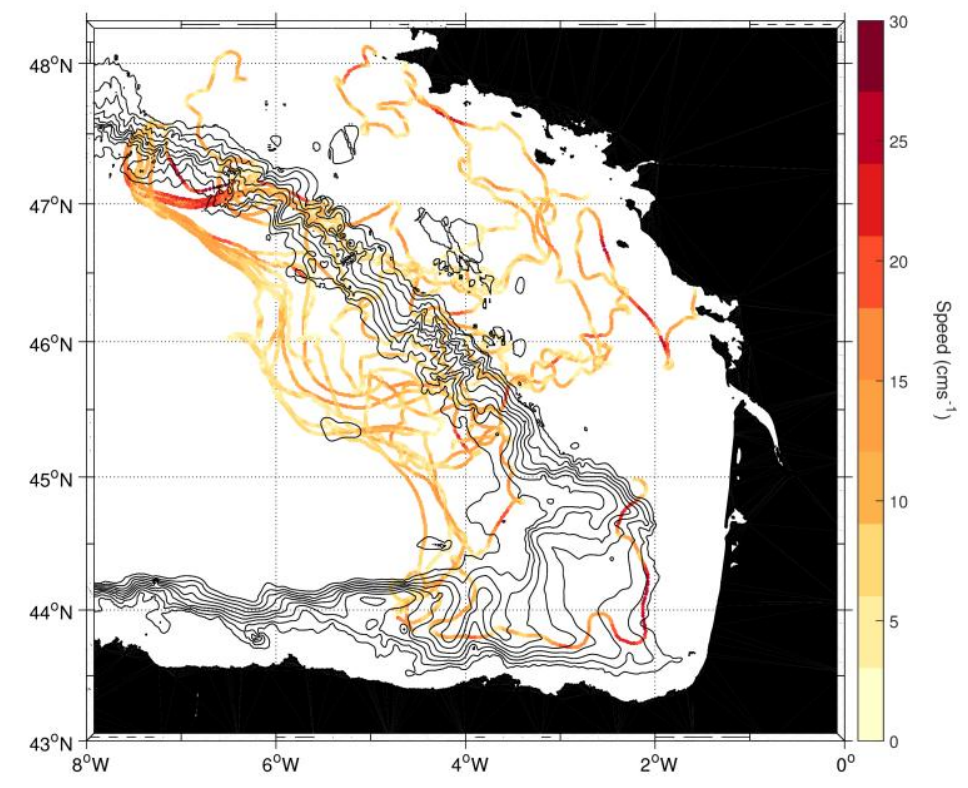

Figure 3 


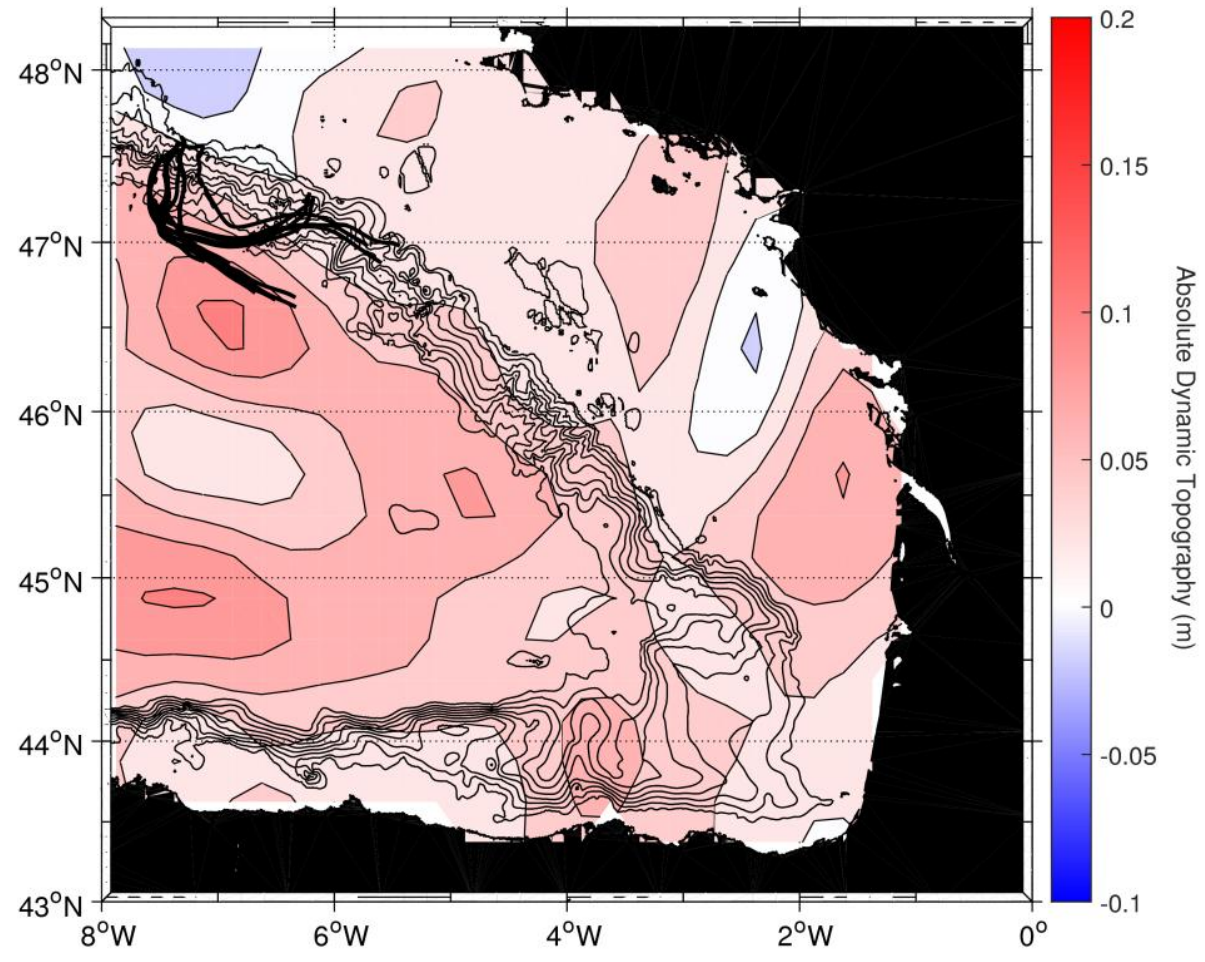

Figure 4a 


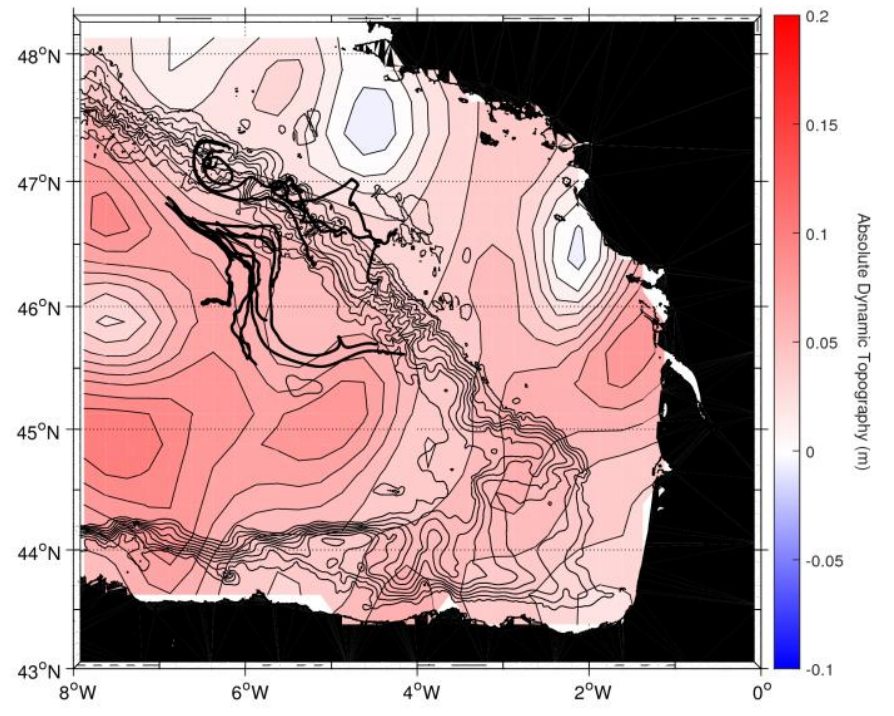

Figure 4b 


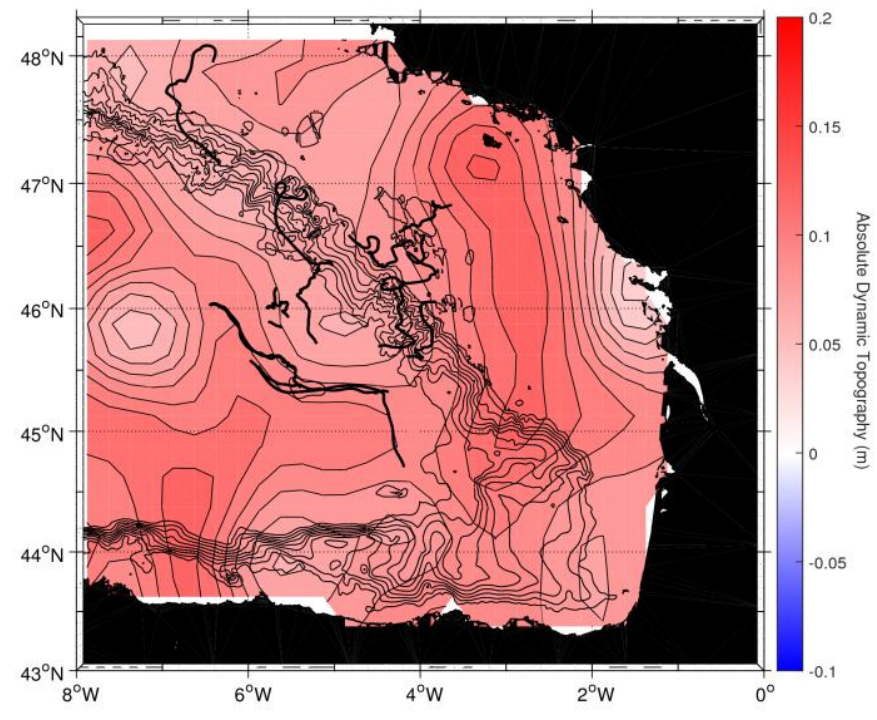

Figure 4c 


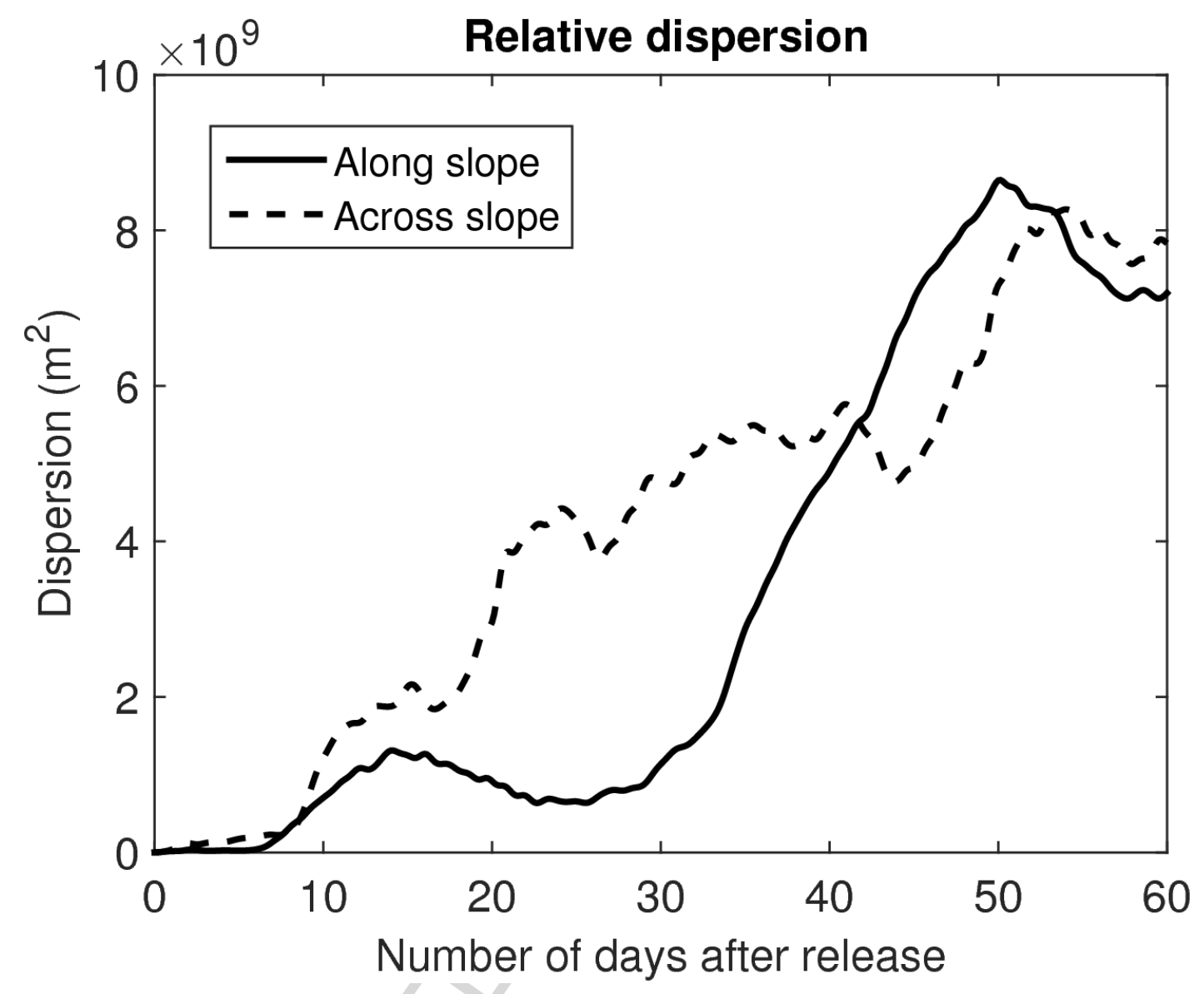

Figure 5 

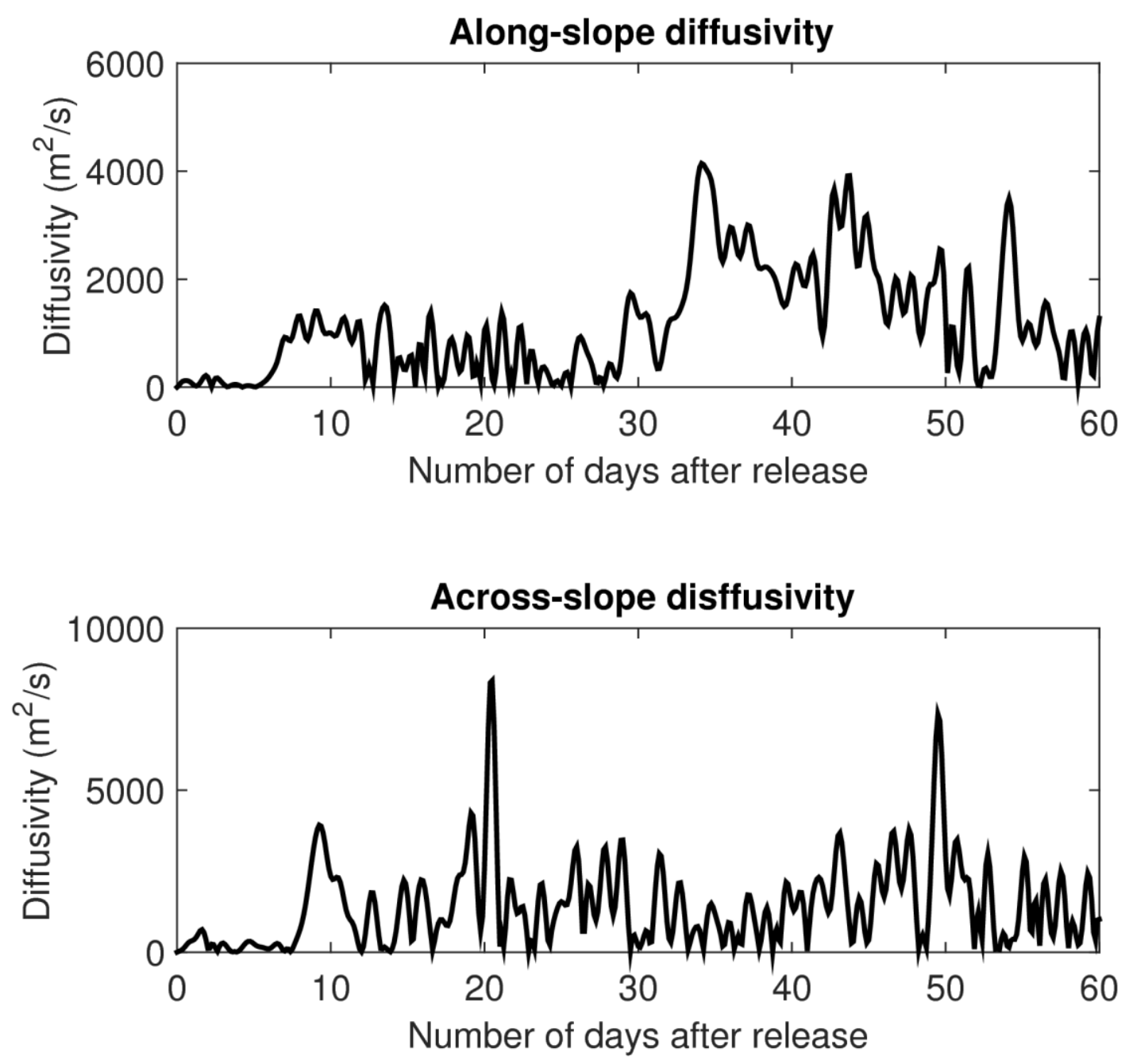

Figure 6 


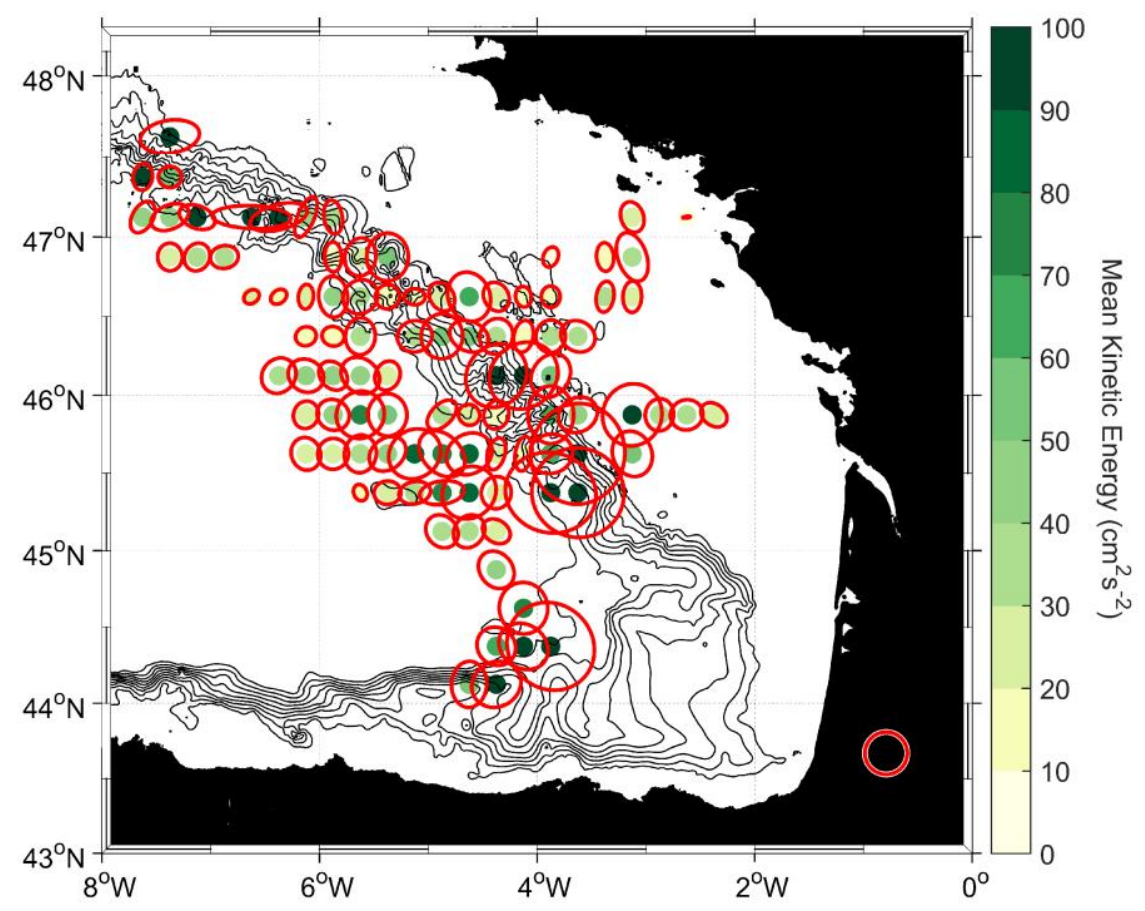

Figure 7 


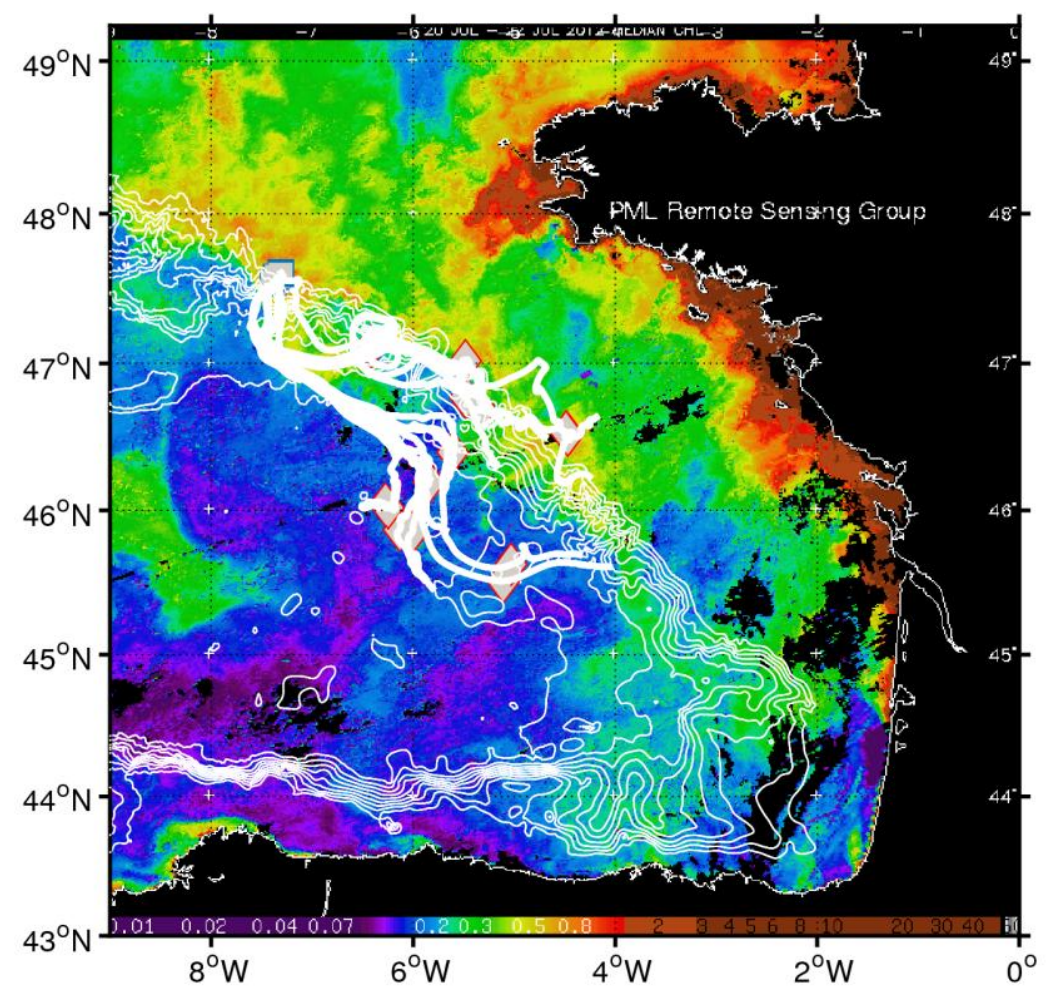

Figure 8a 


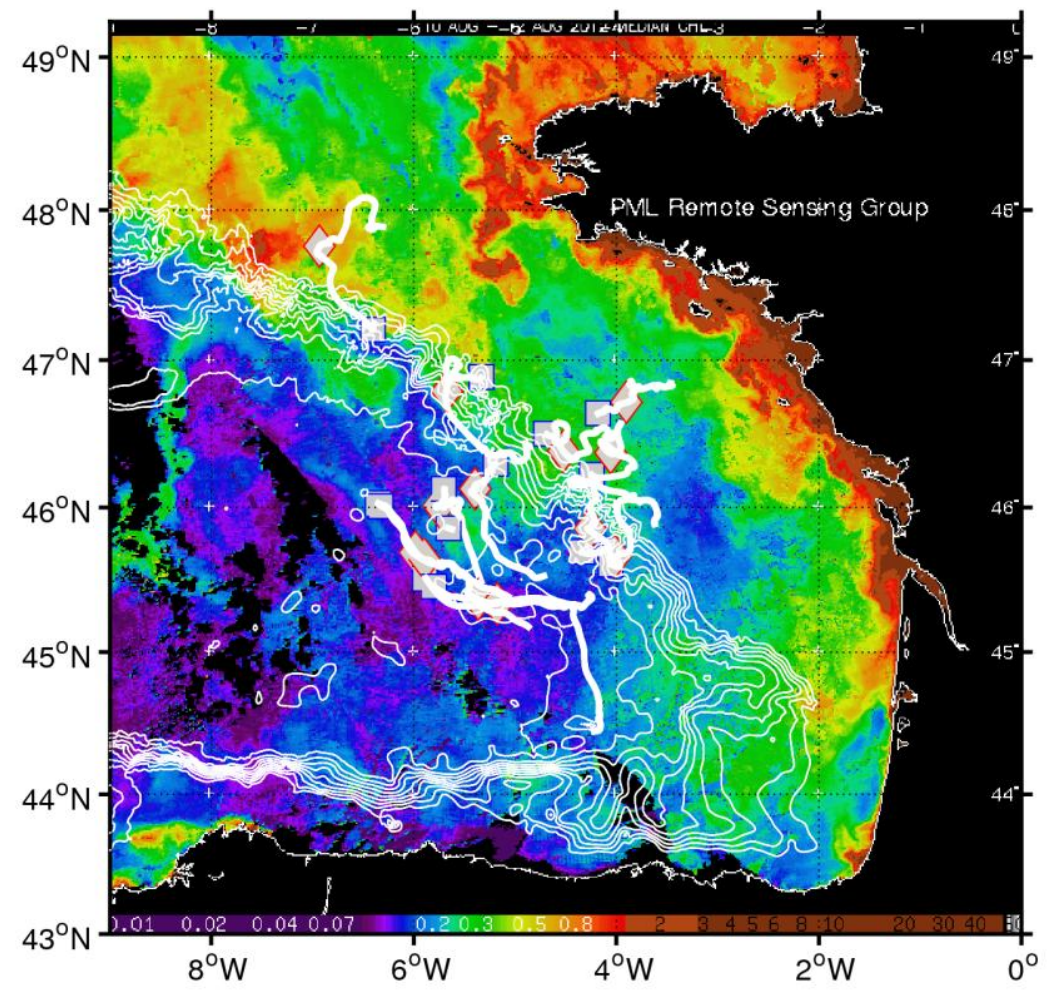

Figure 8b 


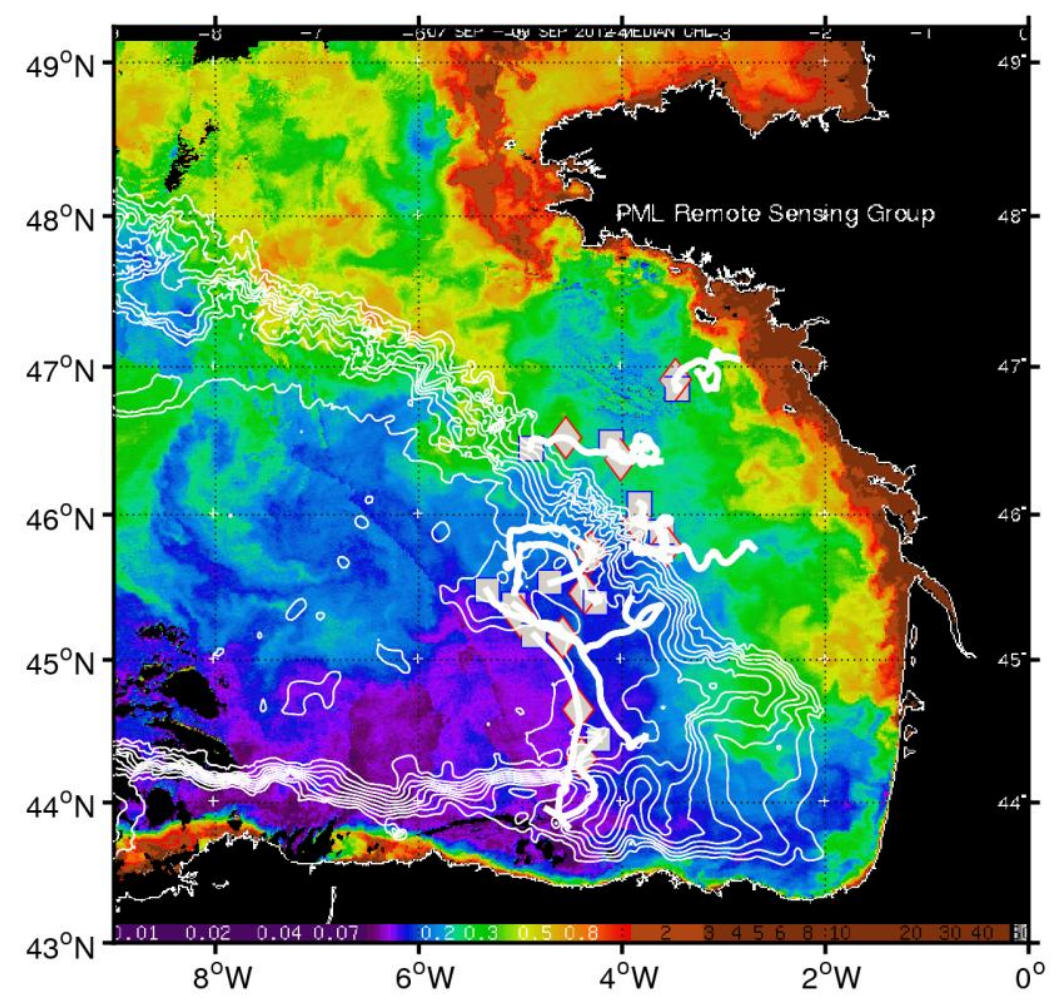

Figure 8c 


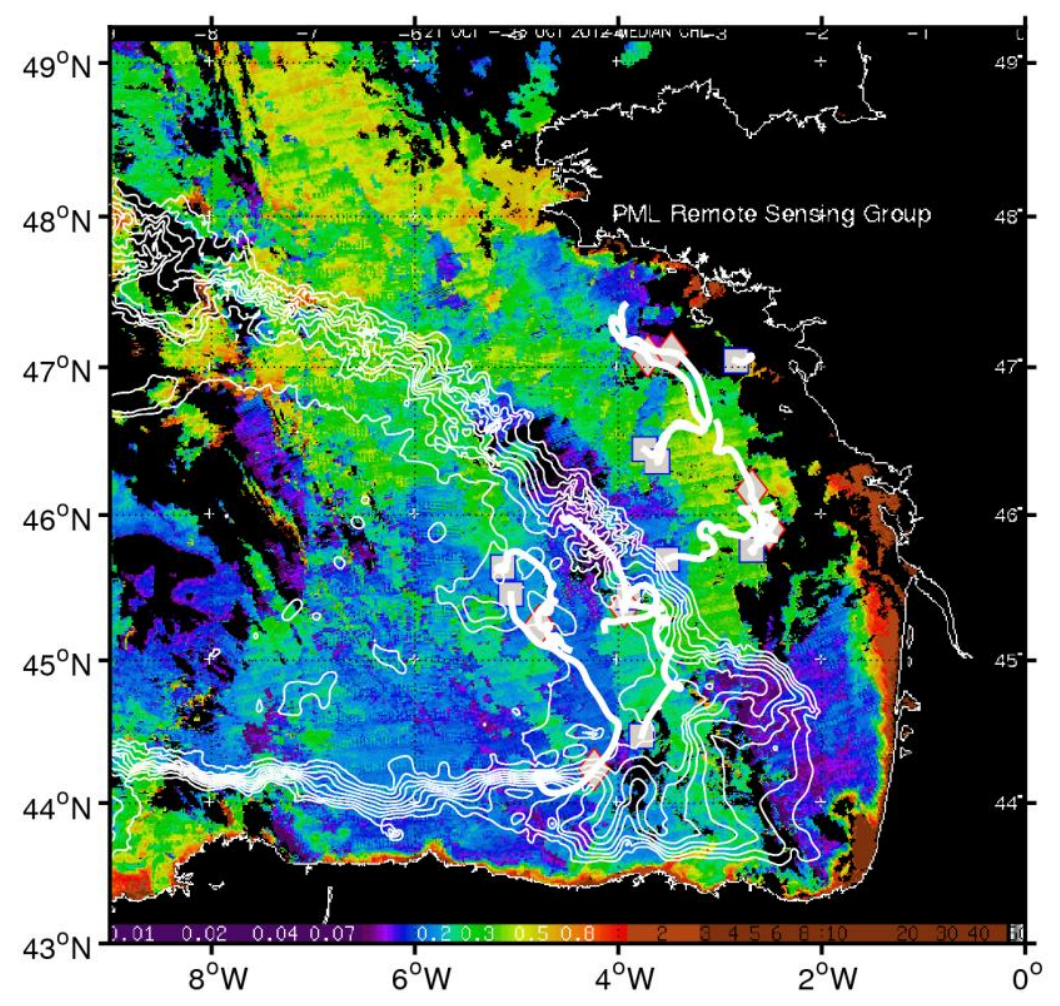

Figure 8d 


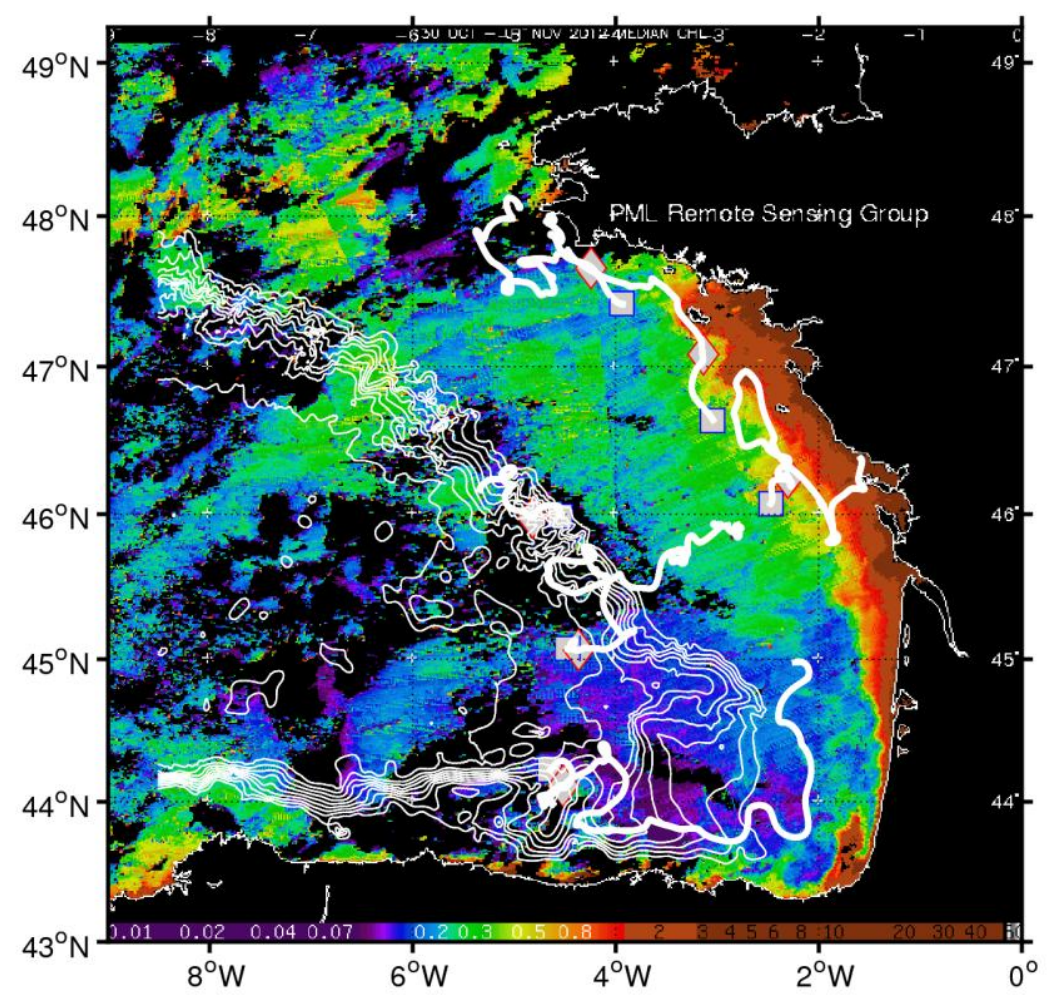

Figure 8e 


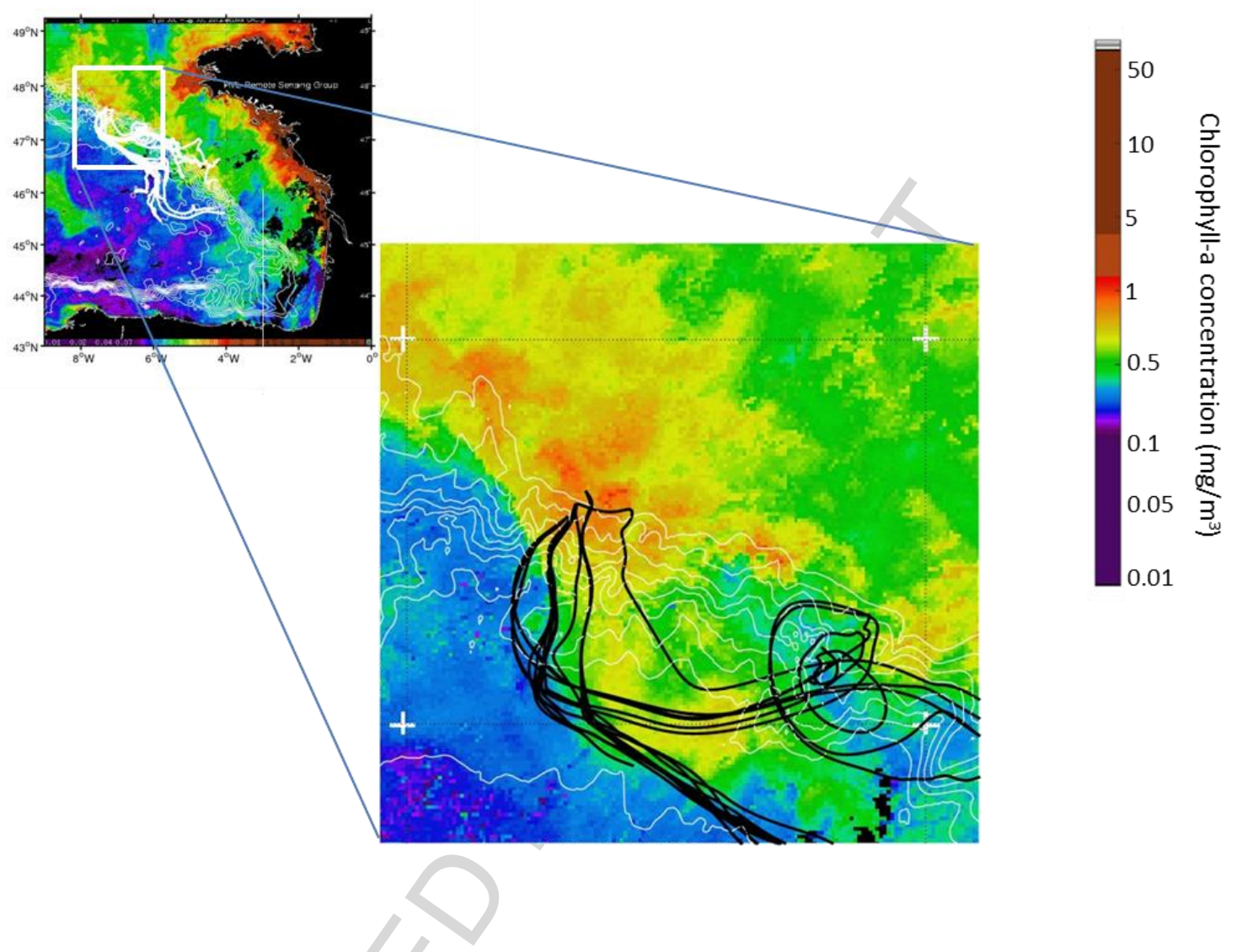

Figure 9 


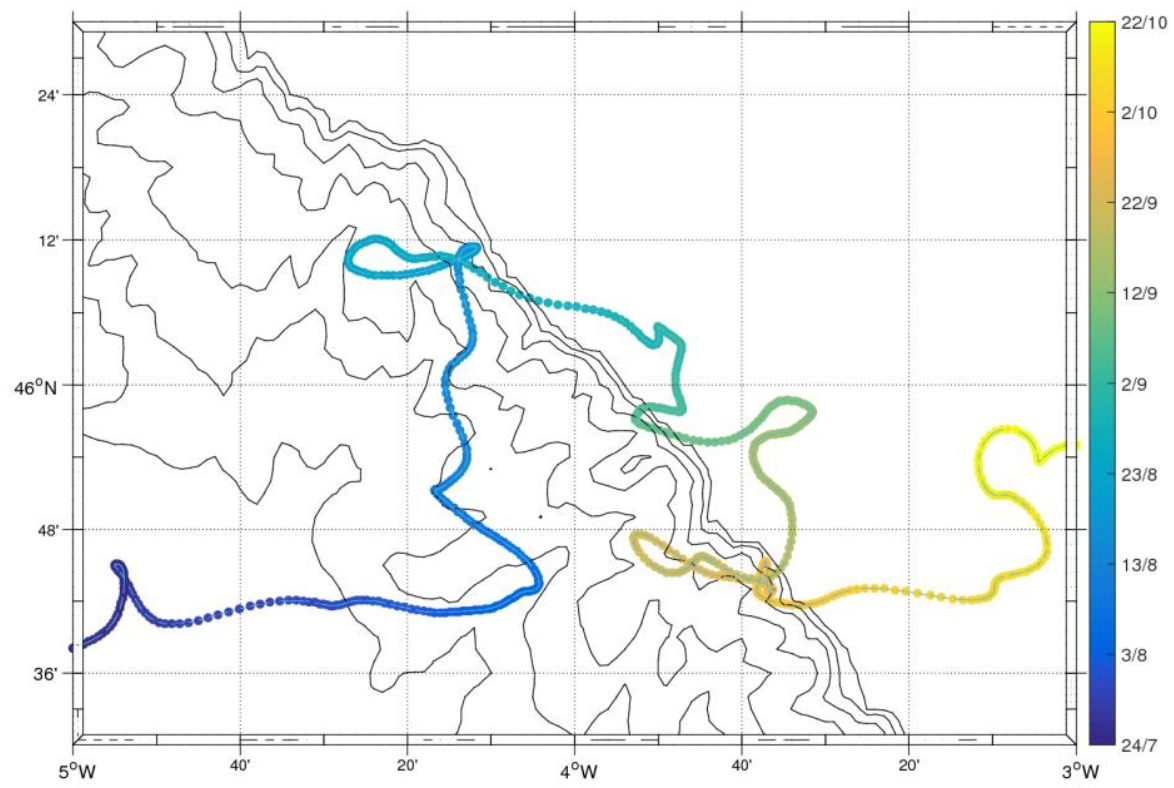

Figure 10 
Table Captions

Table 1

The day of failure of each drifter and the reason for the failure. Throughout this work the drifters are considered active until their day of failure.

\begin{tabular}{|c|c|c|c|}
\hline Drifter number & Day of failure & Date & $\begin{array}{l}\text { Reason for ending } \\
\text { transmission }\end{array}$ \\
\hline 1 & 161 & $22 / 11 / 12$ & Drogue loss \\
\hline 2 & 21 & $5 / 7 / 2012$ & Drogue loss \\
\hline 3 & 102 & $24 / 9 / 2012$ & Drogue loss \\
\hline 4 & 97 & $19 / 9 / 2012$ & Drogue loss \\
\hline 5 & 14 & $28 / 6 / 2012$ & Drogue loss \\
\hline 6 & 202 & $2 / 1 / 2013$ & Picked up by boat \\
\hline 7 & 29 & $13 / 7 / 2012$ & Drogue loss \\
\hline 8 & 62 & $15 / 8 / 2012$ & Caught on bottom \\
\hline 9 & 11 & $25 / 6 / 2012$ & Transmission failure \\
\hline 10 & 215 & $15 / 1 / 2012$ & Drogue loss \\
\hline 11 & 35 & $19 / 7 / 2012$ & Drogue loss \\
\hline 12 & 48 & $1 / 8 / 2102$ & Drogue loss \\
\hline 13 & 190 & $21 / 12 / 2102$ & Caught on bottom \\
\hline 14 & 119 & $11 / 10 / 2102$ & Drogue loss \\
\hline 15 & 74 & $27 / 8 / 2012$ & Transmission failure \\
\hline 16 & 165 & $26 / 11 / 2012$ & Transmission failure \\
\hline 17 & 140 & $1 / 11 / 2102$ & Drogue loss \\
\hline 18 & 124 & $16 / 10 / 2012$ & Caught on bottom \\
\hline 19 & 220 & $20 / 1 / 2013$ & Drogue loss \\
\hline 20 & 11 & $25 / 6 / 2012$ & Transmission failure \\
\hline
\end{tabular}




\section{Highlights}

- $\quad$ A summer release of 20 drifters on the Bay of Biscay slope

- $\quad$ Lagrangian statistics for the Bay of Biscay reveal diffusive system

- $\quad$ On-shelf flow through genesis of small, anticyclonic eddies over complex topography 